\title{
Potential benefits of phenolics from pomegranate pulp and peel in Alzheimer's disease: antioxidant activity and inhibition of acetylcholinesterase
}

\author{
Maressa Caldeira Morzelle ${ }^{\mathrm{a}, \mathrm{b}}$, Jocelem Mastrodi Salgado ${ }^{\mathrm{b}}$, Adna Prado Massarioli ${ }^{\mathrm{b}}$, \\ Patricia Bachiega $^{\mathrm{b}}$, Alessandro de Oliveira Rios ${ }^{\mathrm{c}}$, Severino Matias Alencar ${ }^{\mathrm{b}}$, \\ Andrés R. Schwemberd and Adriano Costa de Camargo ${ }^{\text {b,d* }}$
}

\begin{abstract}
${ }^{\text {aDepartment }}$ f Food and Nutrition, Faculty of Nutrition, Federal University of Mato Grosso, Fernando Correa Avenue, P.O. box 2367, 78060-900 Cuiabá, MT, Brazil

bDepartment of Agri-food Industry, Food and Nutrition, "Luiz de Queiroz" College of Agriculture, University of São Paulo, Pádua Dias Avenue, P.O. Box. 9, 13418-900 Piracicaba, SP, Brazil

${ }^{\mathrm{c} B i o a c t i v e}$ Compounds Laboratory, Food Science and Technology Institute, Federal University of Rio Grande do Sul, Av. Bento Gonçalves n. 9500, PO Box 15059, 91501-970 Porto Alegre, RS, Brazil

dDepartamento de Ciencias Vegetales, Facultad de Agronomía e Ingeniería Forestal, Pontificia Universidad Católica de Chile, Casilla 30622, Santiago, Chile

*Corresponding author: Adriano Costa de Camargo, Department of Agri-food Industry, Food and Nutrition, "Luiz de Queiroz" College of Agriculture, University of São Paulo, Pádua Dias Avenue, P.O. Box. 9, 13418-900 Piracicaba, SP, Brazil. E-mail: adrianoesalq@gmail.com DOI: $10.31665 / J F B .2019 .5181$

Received: March 01, 2019; Revised received \& accepted: March 21, 2019

Citation: Morzelle, M.C, Salgado, J.M, Massarioli, A.P, Bachiega, P., de Oliveira Rios, A., Alencar, S.M, Schwember, A.R., and de Camargo, A.C. (2019). Potential benefits of phenolics from pomegranate pulp and peel in Alzheimer's disease: Antioxidant activity and inhibition of acetylcholinesterase. J. Food Bioact. 5: 136-141.
\end{abstract}

\begin{abstract}
Oxidative stress plays an important role in Alzheimer's disease. To arrest oxidative stress, this contribution first identified and quantified phenolic bioactives present in the pulp and peel of pomegranate using high-performance liquid chromatography. Punicalagin $\beta$ rendered the greatest antiradical activity as evaluated by on-line HPLC-ABTS method, which was followed by punicalagin $\alpha$, gallic acid, and epicatechin. Furthermore, the scavenging activity against peroxyl and DPPH radicals, as well as the reducing power were investigated. Extracts obtained from the peel showed much higher phenolic contents and antioxidant properties than that of the pulp, hence being selected as potential inhibitor of acetylcholinesterase, a key enzyme involved in the progress of Alzheimer's disease. Phenolics from pomegranate peel showed inhibition of acetylcholinesterase, which was dependent on the phenolic concentration. Therefore, pomegranate peel may be considered by the industry as a functional food ingredient and possibly for manufacturing of nutraceuticals.
\end{abstract}

Keywords: Punica granatum L.; Phenolic profile; Antiradical activity; Reducing power; Acetylcholinesterase.

\section{Introduction}

Pomegranate (Punica granatum L.) and its processing by-products are rich sources of phenolic antioxidants (Ambigaipalan et al, 2016, 2017; Yang et al., 2016). In recent years, the interest in this fruit has increased due to scientific evidence supporting its numerous benefits to human health (Akhtar et al., 2015). In fact, pomegranate bioactives have been reported to potentially prevent and/or reduce the risk of development of atherosclerosis, Alzheimer's disease, and certain types of cancer (Al-Jarallah et al., 2013; 
Ambigaipalan et al., 2016, 2017; Morzelle et al., 2016).

Oxidative stress induced by excess free radicals plays a critical role in LDL-cholesterol oxidation and DNA damage, which are well accepted biomarkers for potential development of cardiovascular diseases and cancer (Amarowicz and Pegg, 2017; Khanna and Jackson, 2001). Furthermore, Alzheimer's disease progression has also been reported to be enhanced by oxidative stress (Pohanka, 2014). Therefore, the role of oxidative stress in severe diseases is clear and requires attention.

Acetylcholinesterase (AChE) and butyrylcholinesterase $(\mathrm{BChE})$ are the key enzymes during the progress of Alzheimer's disease. Cholinesterase inhibitors have shown consistent efficacy towards mild, moderate and severe types of Alzheimer's disease. However, treatment with blockers of the acetylcholine-degrading enzyme acetylcholinesterase are obviously prone to many sideeffects (Maelicke and Albuquerque, 2000). Galantamine, an anticholinesterase drug, is originated from a plant material. Therefore, increasing the options of natural compounds bearing acetylcholinesterase could be helpful.

Beta-amyloid protein, a pro-inflammatory agent, is among the main pathologic features of Alzheimer's disease. Patients under nonsteroidal anti-inflammatory drug treatment have been reported to show a lower risk of development of Alzheimer's disease than those who were not under medication (Tuppo and Arias, 2005). Several plant food phenolics have been shown to exhibit anti-inflammatory effects (Melo et al., 2015; Zhang and Tsao, 2016). Therefore, the anti-inflammatory effect of phenolic compounds may be helpful in the management and/or prevention of Alzheimer's disease.

Although the neuroprotective effects of pomegranate peel extract after chronic infusion with amyloid- $\beta$ peptide in mice has been demonstrated, it was not possible to state if the protective effect was only due to acetylcholinesterase inhibition or a combination of it with the anti-inflammatory effects of the phenolics present in the test sample (Morzelle et al., 2016). Furthermore, phenolics may modulate gene expression (Shahidi and de Camargo, 2016). Therefore, it is unclear if the results could be attributed to inhibition of acetylcholinesterase activity or inhibition of neuronal acetylcholinesterase gene expression. Hence, to shed further light in the potential bioactivity of phenolics from pomegranate peel, the inhibitory effect of phenolic extracts was evaluated towards commercial acetylcholinesterase in vitro. The antioxidant potential was also evaluated due to its pivotal role in Alzheimer's disease. Phenolic acids, monomeric flavonoids, and punicalagins were positively identified and quantified by HPLC. In addition, the contribution of major phenolics of test samples were screened for their antiradical activity using an on-line HPLC-ABTS radical cation method.

\section{Materials and methods}

\subsection{Material}

The pomegranate fruits (species Wonderful) were purchased from CEAGESP, São Paulo, Brazil. The fruit was imported from the United States. The peel was separated from the pulp and seeds. The samples were stored in laminated polyethylene at $4{ }^{\circ} \mathrm{C}$ until use.

\subsection{Chemicals}

The compounds 2,2-diphenyl-1-picrylhydrazyl (DPPH), 2,2'-azino-bis(3-ethylbenzothiazoline-6-sulfonic acid) diammonium salt (ABTS), 6-hydroxy-2,5,7,8-tetramethylchroman-2-carboxylic acid (trolox), 2,4,6-tris(2-pyridyl)-S-triazine (TPTZ), 2,2'-azobis(2amidinopropane) dihydrochloride (AAPH), physostigmine, acetylcholinesterase, acetylthiocholine iodide, 5,5'-dithio-bis(2-nitrobenzoic acid) (DTNB), Folin-Ciocalteu, punicalagin $\alpha$ and $\beta$, rutin, quercetin, epicatechin, gallic acid, ferulic acid, $p$-coumaric acid, delphinidin 3-glucoside, cyanidin 3-glucoside, cyanidin-3,5diglucoside, pelargonidin 3,5-diglucoside and pelargonidin 3-glucoside were purchased from Sigma Aldrich (St. Louis, MO, USA). Tris- $\mathrm{HCl}$ was purchased from Merck (Merck, Darmstadt, Germany). Chromatographic solvents were HPLC-grade and the remaining chemicals and solvents were of analytical grade.

\subsection{Phenolic extraction}

The extracts were prepared using 80\% ethanol [1:10 sample/solvent ratio $(\mathrm{m} / \mathrm{v})]$ (Qu et al., 2010). The samples were extracted in shaker table (Model ET-1401, Tecnal, Piracicaba, SP, Brazil) protected from light at room temperature $\left(24 \pm 2{ }^{\circ} \mathrm{C}\right)$ for 24 hours. The resulting extract was centrifuged at $1956.2 \mathrm{~g}$ (Model NT 825, New Technique, Brazil) and the supernatant was concentrated at $35^{\circ} \mathrm{C}$ using a rotary evaporator (Model 801, Fisatom, Brazil). The extracts were stored at $-80^{\circ} \mathrm{C}$ for further analysis. Chemical analyses were then performed on the pulp and peel extracts.

\subsection{Phenolic composition using high-performance liquid chro- matography (HPLC)}

The identification of major phenolic compounds was performed on a high-performance liquid chromatography (HPLC) system (Shimadzu 20A, Shimadzu Co., Kyoto, Japan), equipped with a pumping system (LC-20 AT), autosampler (SIL-20AHT), column oven (CTO-20A), communicator (CBM-20A) and UV/Vis detector (SPD-20A). Phenolic acids and monomeric flavonoids were separated on a Spherisorb ODS-C18 column $(4.6 \times 250 \mathrm{~mm} \times 5 \mu \mathrm{m}$, Waters, Milford, MA, USA) at $35^{\circ} \mathrm{C}$. The injection volume was $10 \mu \mathrm{L}$. Data acquisition and processing were performed using LC solution software (Kyoto, Japan). The mobile phase consisted of $1 \%$ formic acid (A) and methanol (B). The flow rate was adjusted to $0.7 \mathrm{~mL} \mathrm{~min}^{-1}$. The detection of monomeric flavonoids and phenolic acids was carried out at 280 and $370 \mathrm{~nm}$, respectively, while anthocyanins were detected at $520 \mathrm{~nm}$. The elution gradient used was as follows: $0-60 \% \mathrm{~B}$ for $45 \mathrm{~min}$; $100 \% \mathrm{~B}, 50 \mathrm{~min}$; $100 \% \mathrm{~A}$, $60 \mathrm{~min}$ (He et al., 2011). To improve the method performance, punicalagins were separated with the same HPLC system and column but with a different solvent system. The mobile phase consisted of acetonitrile (A) and 1\% formic acid (B). The elution gradient used was as follows: $97 \% \mathrm{~B}, 0 \mathrm{~min} ; 95 \% \mathrm{~B}, 5 \mathrm{~min}, 85 \% \mathrm{~B}, 10 \mathrm{~min} ; 70 \%$ B, 16 min; $97 \%$ B, 18 min, held at 97\% B from $18-30$ min. The flow rate was adjusted to $1 \mathrm{~mL} \mathrm{~min}{ }^{-1}$. The injection volume was $10 \mu \mathrm{L}$, the column temperature was $40{ }^{\circ} \mathrm{C}$, and the detector was set at $260 \mathrm{~nm}$. Phenolic compounds were identified by comparing their retention times and UV spectral data with coded and authentic standards under the same conditions as the samples. Calibration curves were used for quantification.

\subsection{On-line HPLC-ABTS radical cation scavenging activity}

The identification of phenolics was performed on a Shimadzu 20A high-performance liquid chromatography (HPLC) system equipped with a SPD-M10AVP photodiode array detector (DAD) and a SPD-20A UV/vis detector (Shimadzu Co., Kyoto, Japan). 
Separations were conducted on an ODS-A C18 column $(4.6 \times 250$ $\mathrm{mm} \times 5 \mu \mathrm{m}$ ). The extracts were filtered using a $0.22 \mu \mathrm{m}$ filter (Millipore) before the injection $(10 \mu \mathrm{L})$. The mobile phases consisted of $1 \%$ formic acid (A) and methanol (B). The flow rate was adjusted to $0.7 \mathrm{~mL} \mathrm{~min}-1$ and the elution gradient used was as follows: 0 $\min , 100 \%$ A, $45 \min 40 \%$ A, 50 min $100 \%$ A, which was followed by column equilibration from 50 to $60 \mathrm{~min}$ (He et al., 2011). The compounds were identified using UV spectral data and by comparing their retention times with coded and authentic standards. The contribution of individual phenolics to the ABTS radical scavenging activity was evaluated using an HPLC-ABTS radical cation scavenging method (Tiveron et al., 2016; Tremocoldi et al., 2018). A stock solution containing $140 \mathrm{nM}$ potassium persulfate and 7 mM ABTS was prepared and kept at $25^{\circ} \mathrm{C}$ in the dark for 16 hours. The stock solution was diluted in methanol to obtain an absorbance of $0.700 \pm 0.02$ at $734 \mathrm{~nm}$. Each phenolic compound previously separated by HPLC reacted with the ABTS radical cation in the online system. The ABTS radical cation flow was adjusted to $0.7 \mathrm{~mL}$ $\mathrm{min}^{-1}$, the absorbance was monitored at $734 \mathrm{~nm}$ and the scavenging activity was calculated according to their respective negative peaks. The results were expressed as trolox equivalents.

\subsection{DPPH radical scavenging activity (DRSA)}

The test samples were screened for their ability to scavenge DPPH radicals (Brand-Williams et al., 1995). The phenolic extract (0.50 $\mathrm{mL})$ was added to ethanol $(3.0 \mathrm{~mL})$ and a $60 \mu \mathrm{M}$ DPPH solution $(300 \mu \mathrm{L})$. After $45 \mathrm{~min}$ in the dark, the absorbance of the mixture was read at $517 \mathrm{~nm}$ using a UV-visible spectrophotometer (UNICO Instrument Co.) (de Camargo et al., 2012). The radical scavenging activity was calculated using the following equation.

$$
\begin{aligned}
& \text { DPPH radical scavenging activity }(\%)=[(\mathrm{Ab}- \\
& \left.\left.\mathrm{s}_{\text {control }}-\mathrm{Abs}_{\text {sample }}\right) /\left(\mathrm{Abs}_{\text {control }}\right)\right] \times 100
\end{aligned}
$$

where $\mathrm{Abs}_{\text {control }}$ is the absorbance of DPPH radical + ethanol and $\mathrm{Abs}_{\text {sample }}$ is that of DPPH radical + phenolic extract or trolox. The results were expressed in $\mu \mathrm{M}$ trolox equivalent $\mathrm{g}^{-1}$ of phenolic extract.

\subsection{Oxygen radical absorbance capacity (ORAC)}

The ORAC assay was performed as described by Melo et al. (2015). The extracts were diluted in $75 \mathrm{mM}$ potassium phosphate buffer ( $\mathrm{pH} 7.4)$. In a microplate, each extract $(30 \mu \mathrm{L})$ was mixed with $508.25 \mathrm{mM}$ fluorescein $(60 \mu \mathrm{L})$, and $76 \mathrm{mM} \mathrm{AAPH}(110 \mu \mathrm{L})$ which was followed by incubation at $37{ }^{\circ} \mathrm{C}$ in a microplate reader (Molecular Devices, LLC, Sunnyvale, CA, USA). The absorbance was read every min for $2 \mathrm{~h}$ and the excitation and emission wavelength were set to 485 and $528 \mathrm{~nm}$, respectively. The results were expressed as $\mu \mathrm{mol}$ trolox equivalent $\mathrm{g}^{-1}$ of phenolic extract.

\subsection{Ferric reducing antioxidant power (FRAP)}

The reducing power assay (Benzie and Strain, 1996) was based on the method described by de Camargo et al. (2014). The FRAP reagent, which is a mixture $[25 \mathrm{~mL}$ of acetate buffer (acetate 300 $\mathrm{mM}, \mathrm{pH}=3.6)+2.5 \mathrm{~mL}$ of TPTZ $10 \mathrm{mM} \mathrm{TPTZ}$ in $40 \mathrm{mM} \mathrm{HCl}$ ) $+2.5 \mathrm{~mL}$ of $\mathrm{FeCl}_{3}(20 \mathrm{mM}$ in aqueous solution)] was prepared at the time of analysis. Phenolic extracts $(90 \mu \mathrm{L})$ were added to the FRAP reagent $(2.7 \mathrm{~mL})$. The absorbance was read at $595 \mathrm{~nm}$ using
Table 1. Quantification of phenolic compounds $\left(\mu \mathrm{g} \mathrm{g}^{-1}\right)$ in extracts of pomegranate peel and pulp using high-performance liquid chromatog-

\begin{tabular}{|c|c|c|}
\hline & Pulp & Peel \\
\hline \multicolumn{3}{|l|}{ Phenolic acids } \\
\hline Gallic acid & $193.0 \pm 11.3 b$ & $1,005 \pm 8.23 a$ \\
\hline$p$-coumaric & $6.40 \pm 0.24 b$ & $23.20 \pm 1.16 a$ \\
\hline Ferulic acid & $13.30 \pm 0.84 b$ & $103.2 \pm 1.52 a$ \\
\hline \multicolumn{3}{|l|}{ Flavonoids } \\
\hline Epicatechin & $18.55 \pm 1.42 b$ & $198.4 \pm 11.4 a$ \\
\hline Rutin & $8.97 \pm 0.69 b$ & $144.6 \pm 4.09 a$ \\
\hline \multicolumn{3}{|l|}{ Hydrolysable tannins } \\
\hline Punicalagin $\alpha$ & $63.0 \pm 2.0 \mathrm{~b}$ & $7,500 \pm 11.0 a$ \\
\hline Punicalagin $\beta$ & $66.0 \pm 4.0 \mathrm{~b}$ & $6,241 \pm 10.0 a$ \\
\hline \multicolumn{3}{|l|}{ Anthocyanins } \\
\hline Cyanidin-3,5-diglucoside & $5573 \pm 20.8 b$ & $23,573 \pm 20.8 a$ \\
\hline Delphinidin 3-glucoside & $9430 \pm 10.0 b$ & $50,640 \pm 20.0 a$ \\
\hline Pelargonidin 3,5-diglucoside & $870.0 \pm 10.0 b$ & $8,053 \pm 25.2 a$ \\
\hline Cyanidin 3-glucoside & $756.7 \pm 11.5 b$ & $22,830 \pm 10.0$ \\
\hline Pelargonidin 3-glucoside & $870.0 \pm 10.0 b$ & $8,053 \pm 25.2 a$ \\
\hline
\end{tabular}
raphy (HPLC)

Data represent mean values for each sample \pm standard deviation $(n=3)$. Means followed by different lower case letters within a row show difference between the samples $(p<0.0001)$. Abbreviations: GAE, gallic acid equivalents; $\mathrm{QE}$, quercetin equivalents.

using a UV-visible spectrophotometer (UNICO Instrument Co.) after incubation in a water bath at $37^{\circ} \mathrm{C}$ for $30 \mathrm{~min}$. The results were expressed in $\mu \mathrm{mol}$ iron sulphate $\mathrm{g}^{-1}$ of phenolic extract.

\subsection{AChE inhibition assay}

The photometric method described by Ellman et al. (1961) was used to determine acetylcholinesterase activity. Physostigmine (1 $\mathrm{mg} \mathrm{mL}^{-1}$ ) was used as the positive control. The reaction rates were calculated using GraphPad Prism software (version 5.0) and the $\mathrm{IC}_{50}$ values were determined.

\subsection{Statistical analysis}

The experimental design was randomized with four replicates and the results expressed as mean \pm standard deviation. The results were submitted to analysis of variance (ANOVA) using SAS software and $\mathrm{F}$ test $(p<0.05)$.

\section{Results and discussion}

\subsection{Identification and quantification of phenolic compounds by high performance liquid chromatography}

Pomegranate peel extracts contained a higher amount of total phenolics $\left(128.4 \mathrm{mg} \mathrm{g}^{-1}\right)$ in relation to that of pomegranate pulp 
Table 2. Radical scavenging activity ( $\mu \mathrm{mol} \mathrm{TE} \mathrm{g}^{-1} \mathrm{DW}$ ) of pomegranate peel and pulp extracts by HPLC-DAD-ABTS on-line

\begin{tabular}{lllll}
\hline \multirow{2}{*}{ Sample } & \multicolumn{3}{c}{ Compound } \\
\cline { 2 - 5 } & gallic acid & epicatechin & punicalagin $\boldsymbol{\alpha}$ & punicalagin $\boldsymbol{\beta}$ \\
\hline Peel & $860.62 \pm 20.24^{\mathrm{c}}$ & $545.53 \pm 23.17^{\mathrm{d}}$ & $1,129.73 \pm 43.90^{\mathrm{b}}$ & $1,324.98 \pm 49.59^{\mathrm{a}}$ \\
Pulp & $124.04 \pm 3.28^{\mathrm{c}}$ & $119.59 \pm 1.34^{\mathrm{c}}$ & $140.04 \pm 2.33^{\mathrm{b}}$ & $299.09 \pm 0.86^{\mathrm{a}}$ \\
\hline
\end{tabular}

Data represent mean values for each sample \pm standard deviation $(n=3)$. Means followed by different lower case letters within a row show difference between the samples $(p<$ 0.0001 ). Abbreviations are: TE, trolox equivalents; and DW, dry weight of phenolic extract.

(17.9 $\mathrm{mg} \mathrm{g}^{-1}$ ) extracts (Table 1), as evaluated by HPLC. Likewise, pomegranate pulp extracts showed a lower content of total flavonoids $\left(17.6 \mathrm{mg} \mathrm{g}^{-1}\right)$ compared to that of the peel extracts $(127.2$ $\mathrm{mg} \mathrm{g}^{-1}$ ). Various studies have shown that fruit by-products serve as excellent sources of phenolic compounds (Madrigal-Carballo et al., 2009; Mastrodi Salgado et al., 2012). Furthermore, their biological activity has been demonstrated in several model systems in relation to their protective role in prevention of human LDL-cholesterol oxidation and DNA damage, which are biomarkers related to cardiovascular disease and cancer development, respectively.

Gallic acid was the main phenolic acid in both tested samples (Table 1), followed by ferulic acid. The concentration of the latter one was 7.8-fold higher in the peel compared to the pulp. The presence of $p$-coumaric acid was also noted. Epicatechin and rutin were the monomeric flavonoids present. Structure/activity discussions have been in the spotlight due to their potential in anticipating potential benefits under physiological conditions. While all phenolic acids and epicatechin are simple phenolics (aglycones), rutin is a quercetin molecule linked to a sugar moiety (quercetin3-O-rutinoside). Several pieces of evidence have demonstrated phenolic aglycones may be more bioacessible than their conjugated counterparts (Shahidi and Peng, 2018). Likewise, extracts containing high amounts of aglycones also show a higher antiradical activity compared to that of extracts containing their conjugated counterparts (Yoshiara et al., 2018). Amongst the monomeric phenolics, the high content of gallic acid in both samples makes the test materials good candidates as functional foods and/or nutraceutical ingredients. However, considering all phenolics, hydrolysable tannins (punicalagin $\alpha$ and $\beta$ ) made the highest contribution to the phenolic profile of pomegranate peel extract, which is in good agreement with the literature (Ambigaipalan et al., 2016). These bioactive compounds are involved in plant defense against ultraviolet radiation and/or attack by pathogens (Díaz-de-Cerio et al., 2016).

To our knowledge, no genetic study has been reported yet that could explain the differences in the hydrolyzable tannins (HT, i.e., punicalagin) levels between the pulp and the peel pomegranate. However, Ono et al. (Ono et al., 2012) found that the pomegranate hairy root culture system is appropriate for expressing heterologous genes such as yellow fluorescent protein (YFP). In their study, 26 putative UDP-glycosyltransferase (UGT) genes, obtained from a pomegranate fruit peel (a tissue highly abundant in HTs) RNA-Seq library, were expressed and studied in wild type and hairy roots. Additionally, two candidate UGTs for HT biosynthesis were identified based on HPLC and differential gene expression analyses of various pomegranate tissues. In another work, overexpression and single RNAi knockdown pomegranate hairy root lines of two UDP-glucosyltransferase (UGT) genes, UGT84A23 and UGT84A24, did not result in clear changes in punicalagin accumulation, although double knockdown lines of these two UGTs showed reduced levels of punicalagins and bis-hexahydroxydiphenyl glucose isomers. In addition, accumulation of galloyl gluco- sides (ether-linked gallic acid and glucose) was identified in the double knockdown lines, suggesting that gallic acid was used by an unidentified UGT activity for glucoside synthesis, which gives rise to future prospects for understanding the regulatory control of HT metabolism in plants and its coordination with other biochemical pathways in the metabolic network (Ono et al., 2016)

More recently, Qin et al. (2017) sequenced and assembled the pomegranate genome with $328 \mathrm{Mb}$ anchored into nine pseudochromosomes and annotated 29,229 gene models. They discovered that that the integument development gene INNER NO OUTER (INO) was under positive selection and potentially contributed to the development of the fleshy outer layer of the seed coat, an edible part of pomegranate fruit. In addition, the genes encoding the enzymes for synthesis and degradation of cellulose, hemicelluloses and lignin were also differentially expressed between soft-and hard-seeded varieties, showing differences in their accumulation in cultivars differing in seed hardness. In parallel, candidate genes for punicalagin biosynthesis were identified and their expression patterns indicated that gallic acid synthesis in tissues could follow different biochemical pathways. As a result of the sequencing of the pomegranate genome, there will be important opportunities for unraveling and understanding the biochemical pathway(s) involved in the punicalagin biosynthesis that will be very valuable for breeding efforts to increase production of this bioactive compound.

\subsection{Main phenolics from pomegranate pulp and peel as scaven- gers of ABTS radical cation}

Several studies have reported the scavenging properties of phenolics from pomegranate and their processing by-products towards ABTS radical (Ambigaipalan et al., 2016, 2017). However, the individual contribution of pomegranate phenolics to such activity has not yet been entirely clarified. Furthermore, higher concentrations of particular phenolics do not always translate to higher activities. Therefore, to shed light on this situation and to fill an apparent gap in the literature, pomegranate phenolics from pulp and peel were tested against ABTS radical cation by using an online HPLC-ABTS method.

Regardless of the compound, pomegranate peel showed much higher scavenging activity compared to that of pomegranate pulp (Table 2). Amongst pomegranate peel phenolics, punicalagin $\beta$ rendered the greatest antiradical activity as evaluated by on-line HPLC-ABTS method $\left(1,324.9 \pm 49.60 \mu\right.$ mol trolox $\left.\mathrm{g}^{-1}\right)$, which was followed by punicalagin $\alpha\left(1,129.73 \pm 43.90 \mu \mathrm{mol}_{\text {trolox }} \mathrm{g}^{-1}\right)$. Gallic acid, a simple phenolic compound, rendered the third highest antiradical activity $\left(860.62 \pm 20.24 \mu \mathrm{mol}\right.$ trolox $\left.\mathrm{g}^{-1}\right)$, while the monomeric flavonoid epicatechin $(545.53 \pm 23.17 \mu$ mol trolox $\mathrm{g}^{-1}$ ) made the lowest contribution. The same trend was found with respect to the antiradical activity of phenolics from pomegranate pulp. Therefore, irrespective of the source (peel or pulp), ellagitannins (punicalagin $\alpha$ plus $\beta$ ) serve as the most important antioxi- 
Table 3. Antioxidant activities and reducing power of phenolics of pomegranate pulp and peel ${ }^{\mathrm{a}}$

\begin{tabular}{|c|c|c|c|}
\hline & DPPH ( $\mu \mathrm{mol}$ TE $\left.\mathrm{g}^{-1} \mathrm{DW}\right)$ & ORAC ( $\mu \mathrm{mol}$ TE $\left.\mathrm{g}^{-1} \mathrm{DW}\right)$ & FRAP $\left(\mu \mathrm{mol} \mathrm{Fe}^{2+} \mathrm{g}^{-1} \mathrm{DW}\right)$ \\
\hline Pulp & $108.3 \pm 5.95^{b}$ & $323.8 \pm 10.3^{b}$ & $2.47 \pm 0.12^{b}$ \\
\hline Peel & $2,372 \pm 30.5^{a}$ & $7,423 \pm 180^{a}$ & $56.5 \pm 5.90^{a}$ \\
\hline
\end{tabular}

Data represent mean values for each sample \pm standard deviation $(n=3)$. Means followed by different lower case letters within a column show difference between the samples $(p<0.0001)$. Abbreviations are: TE, trolox equivalents; and DW, dry weight of sample.

dants in pomegranate.

\subsection{Phenolics from pomegranate pulp and peel as scavengers of peroxyl radicals and reducing agents}

Reactive oxygen species (ROS), including peroxyl radicals, participate in several detrimental processes in biological systems. Likewise, ferric ions also catalyse oxidative reactions. The relatively long half-life of peroxyl radical makes these ROS potentially deleterious to intracellular components and biological fluids (de Camargo et al., 2014). Peroxyl radical is an intermediate of the Fenton reaction. Likewise, both $\mathrm{Fe}^{2+}$ and $\mathrm{Fe}^{3+}$ participate in the Haber-Weiss cycle, however, the ratio of these two chemical forms is important to the reaction kinetics and the ideal has been reported to be in the range of 1:1 to 7:1 $\left(\mathrm{Fe}^{3+} / \mathrm{Fe}^{2+}\right)$ (Braughler et al., 1986). A lower concentration of $\mathrm{Fe}^{3+}$ may be helpful to stop and/or delay the Fenton reaction, which produces ROS involved in lipid oxidation. Therefore, phenolics from pomegranate pulp and peel were tested against peroxyl radicals (ORAC assay) and for their reducing power (FRAP assay).

In agreement with the results obtained by on-line HPLC-ABTS, phenolics from pomegranate peel were more effective in scavenging peroxyl radicals and in reducing $\mathrm{Fe}^{3+}$ (Table 3 ). In addition, according to the literature, phenolic extracts from pomegranate by-products also chelated $\mathrm{Fe}^{2+}$ and scavenged hydroxyl radicals (Ambigaipalan et al., 2016, 2017). The presence of galloyl moiety in phenolic compounds is important for complex formation with metal ions (Andjelković et al., 2006) and galloyl groups in phenolics from pomegranate juice and their processing by-products have been confirmed by mass spectrometry (Ambigaipalan et al., 2016, 2017; Mena et al., 2012).

\subsection{Acetylcholinesterase (AChE) inhibition}

Pomegranate peel showed a higher total phenolic content, total flavonoids and higher concentration of all individual phenolics, than that of the pulp. As mentioned earlier, oxidative stress plays an important role in Alzheimer's disease. Pomegranate peel also displayed a higher antioxidant activity and reducing power than that of the pulp and was, therefore, evaluated for its potential as a source of phenolics with inhibition capacity towards AChE enzyme. The selected extract showed a dose-dependent inhibition towards AChE $\left(\mathrm{IC}_{50} 2.48 \mathrm{mg} / \mathrm{mL}\right)$. The highest inhibition of AChE $(58 \%)$ was found in extracts at $3 \mathrm{mg} / \mathrm{mL}$, while extracts at $0.3 \mathrm{mg} /$ $\mathrm{mL}$ showed $26 \%$ of inhibition. Ademosun and Oboh (2012) evaluated the effects of some citrus fruit juices (grapefruit, lemon, orange and tangerine) on $\mathrm{AChE}$ activity in vitro. According to these authors, AChE activity was also dose-dependently inhibited by their bioactive compounds. Orange juice, which showed the higher antioxidant activity, also displayed the highest AChE inhibitory activity, thus lending support to the findings of the present study. Therefore, considering data from the literature (Morzelle et al., 2016) and our contribution, dietary inclusion of pomegranate peel extract may prevent Alzheimer's disease, which may at least partly be attributed to their high content of bioactive compounds, their antioxidant capacity and inhibitory activity against AChE.

\section{Conclusion}

The present study demonstrated that pomegranate peel had a higher concentration of total phenolics and flavonoids as well as individual phenolics as evaluated by HPLC compared to those of pomegranate pulp. Irrespective of the starting material, punicalagin $\beta$ rendered the greatest antiradical activity as evaluated by on-line HPLC-ABTS method, which was followed by punicalagin $\alpha$, gallic acid, and epicatechin. Likewise, pomegranate peel showed higher antioxidant activity and reducing power than that of the pulp. Pomegranate peel proved to serve as a rich source of phenolics with potential inhibitory activity against AChE enzyme. The extracts so obtained showed a dose-dependent inhibition towards AChE. Therefore, due to their antioxidant activity, reducing power and inhibitory effect against $\mathrm{AChE}$, pomegranate peel may be used as multifunctional ingredient and a rich source of nutraceuticals.

\section{Acknowledgments}

The first author acknowledges FAPESP (Fundação de Amparo à Pesquisa do Estado de São Paulo), grant \#2013/08989-1 for her Ph.D. fellowship. S. M. Alencar is thankful to FAPESP (grant \#2013/13190-2). A. C. de Camargo acknowledges CAPES - Coordenação de Aperfeiçoamento de Pessoal de Nível Superior, Brazil (process \#88887.169471/2018-00) and Fondo Nacional de Desarrollo Científico y Tecnológico-FONDECYT postdoctorado (project 3180432).

\section{Conflict of interest}

There are no conflicts to declare.

\section{References}

Ademosun, A.O., and Oboh, G. (2012). Inhibition of acetylcholinesterase activity and $\mathrm{Fe}^{2+}$-induced lipid peroxidation in rat brain in vitro by some citrus fruit juices. J. Med. Food 15: 428-434.

Akhtar, S., Ismail, T., Fraternale, D., and Sestili, P. (2015). Pomegranate peel and peel extracts: Chemistry and food features. Food Chem. 174: 417-425.

Al-Jarallah, A., Igdoura, F., Zhang, Y., Tenedero, C.B., White, E.J., MacDonald, M.E., Igdoura, S.A., and Trigatti, B.L. (2013). The effect of pomegranate extract on coronary artery atherosclerosis in SR-BI/APOE double knockout mice. Atherosclerosis 228: 80-89.

Amarowicz, R., and Pegg, R.B. (2017). The potential protective effects of phenolic compounds against low-density lipoprotein oxidation. Curr. 
Pharm. Des. 23: 2754-2766

Ambigaipalan, P., de Camargo, A.C., and Shahidi, F. (2016). Phenolic compounds of pomegranate byproducts (outer skin, mesocarp, divider membrane) and their antioxidant activities. J. Agric. Food Chem. 64: 6584-6604.

Ambigaipalan, P., de Camargo, A.C., and Shahidi, F. (2017). Identification of phenolic antioxidants and bioactives of pomegranate seeds following juice extraction using HPLC-DAD-ESI-MS ${ }^{n}$. Food Chem. 221 1883-1894.

Andjelković, M., Van Camp, J., de Meulenaer, B., Depaemelaere, G., Socaciu, C., Verloo, M., and Verhe, R. (2006). Iron-chelation properties of phenolic acids bearing catechol and galloyl groups. Food Chem. 98: 23-31

Benzie, I.F.F., and Strain, J.J. (1996). The ferric reducing ability of plasma (FRAP) as a measure of "antioxidant power": the FRAP assay. Anal. Biochem. 239: 70-76.

Brand-Williams, W., Cuvelier, M.E., and Berset, C. (1995). Use of a free radical method to evaluate antioxidant activity. LWT Food. Sci. Technol. 28: 25-30.

Braughler, J.M., Duncan, L.A., and Chase, R.L. (1986). The involvement of iron in lipid peroxidation. Importance of ferric to ferrous ratios in initiation. J. Biol. Chem. 261: 10282-10289.

de Camargo, A.C., Vieira, T.M.F.S., Rasera, G.B., Canniatti-Brazaca, S.G. de Alencar, S.M., and Regitano-d'Arce, M.A.B. (2014). Lower solvent concentration and time for extraction of peanut skin antioxidants at optimized conditions. In: Cook, R.W. (Ed.) Peanuts: Production, Nutritional Content and Health Implications. Nova Science Publishers, New York, NY, pp. 31-50.

de Camargo, A.C., Regitano-d'Arce, M.A.B., Biasoto, A.C.T., and Shahidi, F. (2014). Low molecular weight phenolics of grape juice and winemaking byproducts: Antioxidant activities and inhibition of oxidation of human low-density lipoprotein cholesterol and DNA strand breakage. J. Agric. Food Chem. 62: 12159-12171.

de Camargo, A.C., Vieira, T.M.F.S., Regitano-d'Arce, M.A.B., CaloriDomingues, M.A., and Canniatti-Brazaca, S.G. (2012). Gamma radiation effects on peanut skin antioxidants. Int. J. Mol. Sci. 13: 3073-3084.

Díaz-de-Cerio, E., Gómez-Caravaca, A.M., Verardo, V., Fernández-Gutiérrez, A., and Segura-Carretero, A. (2016). Determination of guava (Psidium guajava L.) leaf phenolic compounds using HPLC-DADQTOF-MS. J. Funct. Foods 22: 376-388.

Ellman, G.L., Courtney, K.D., Andres, V., and Featherstone, R.M. (1961). A new and rapid colorimetric determination of acetylcholinesterase activity. Biochem. Pharmacol. 7: 88-95.

He, L., Xu, H., Liu, X., He, W., Yuan, F., Hou, Z., and Gao, Y. (2011). Identification of phenolic compounds from pomegranate (Punica granatum L.) seed residues and investigation into their antioxidant capacities by HPLC-ABTS $^{+}$assay. Food Res. Int. 44: 1161-1167.

Khanna, K.K., and Jackson, S.P. (2001). DNA double-strand breaks: signaling, repair and the cancer connection. Nat. Genet. 27: 247-254.

Madrigal-Carballo, S., Rodriguez, G., Krueger, C.G., Dreher, M., and Reed J.D. (2009). Pomegranate (Punica granatum) supplements: Authenticity, antioxidant and polyphenol composition. J. Funct. Foods 1: 324-329.

Maelicke, A., and Albuquerque, E.X. (2000). Allosteric modulation of nicotinic acetylcholine receptors as a treatment strategy for Alzheimer's disease. Eur. J. Pharmacol. 393: 165-170.

Mastrodi Salgado, J., Baroni Ferreira, T.R., de Oliveira Biazotto, F., and dos Santos Dias, C.T. (2012). Increased antioxidant content in juice en- riched with dried extract of pomegranate (Punica granatum) peel. Plant Foods Hum. Nutr. 67: 39-43.

Melo, P.S., Massarioli, A.P., Denny, C., dos Santos, L.F., Franchin, M., Pereira, G.E., Vieira, T.M.F.S., Rosalen, P.L., and Alencar, S.M. (2015). Winery by-products: Extraction optimization, phenolic composition and cytotoxic evaluation to act as a new source of scavenging of reactive oxygen species. Food Chem. 181: 160-169.

Mena, P., Calani, L., Dall'Asta, C., Galaverna, G., Garcia-Viguera, C., Bruni, R., Crozier, A., and Del Rio, D. (2012). Rapid and comprehensive evaluation of (poly)phenolic compounds in pomegranate (Punica granatum L.) juice by UHPLC-MSn. Molecules 17: 14821-14840.

Morzelle, M.C., Salgado, J.M., Telles, M., Mourelle, D., Bachiega, P., Buck, H.S., and Viel, T.A. (2016). Neuroprotective effects of pomegranate peel extract after chronic infusion with amyloid- $\beta$ peptide in mice. PLoS ONE 11: e0166123.

Ono, N.N., Bandaranayake, P.C.G., and Tian, L. (2012). Establishment of pomegranate (Punica granatum) hairy root cultures for genetic interrogation of the hydrolyzable tannin biosynthetic pathway. Planta 236: 931-941.

Ono, N.N., Qin, X., Wilson, A.E., Li, G., and Tian, L. (2016). Two UGT84 Family glycosyltransferases catalyze a critical reaction of hydrolyzable tannin biosynthesis in pomegranate (Punica granatum). PloS One 11 e0156319.

Pohanka, M. (2014). Alzheimer s disease and oxidative stress: a review. Curr. Med. Chem. 21: 356-364

Qin, G., Xu, C., Ming, R., Tang, H., Guyot, R., Kramer, E.M., Hu, Y., Yi, X., Qi, Y., Xu, X., Gao, Z., Pan, H., Jian, J., Tian, Y., Yue, Z., and Xu, Y. (2017) The pomegranate (Punica granatum $\mathrm{L}$.) genome and the genomics of punicalagin biosynthesis. Plant J. 91: 1108-1128.

Qu, W., Pan, Z., and Ma, H. (2010). Extraction modeling and activities of antioxidants from pomegranate marc. J. Food Eng. 99: 16-23.

Shahidi, F., and de Camargo, A.C. (2016). Tocopherols and tocotrienols in common and emerging dietary sources: Occurrence, applications, and health benefits. Int. J. Mol. Sci. 17: 1745

Shahidi, F., and Peng, H. (2018). Bioaccessibility and bioavailability of phenolic compounds. J. Food Bioact. 4: 11-68.

Tiveron, A.P., Rosalen, P.L., Franchin, M., Lacerda, R.C.C., Bueno-Silva, B., Benso, B., Denny, C., Ikegaki, M., and de Alencar, S.M. (2016). Chemical characterization and antioxidant, antimicrobial, and anti-inflammatory activities of South Brazilian organic propolis. PLoS ONE 11: e0165588.

Tremocoldi, M.A., Rosalen, P.L., Franchin, M., Massarioli, A.P., Denny, C., Daiuto, É.R., Paschoal, J.A.R., Melo, P.S., and de Alencar, S.M. (2018). Exploration of avocado by-products as natural sources of bioactive compounds. PLoS ONE 13: e0192577.

Tuppo, E.E., and Arias, H.R. (2005). The role of inflammation in Alzheimer's disease. Int. J. Biochem. Cell Biol. 37: 289-305.

Yang, J., Lee, R., Henning, S.M., Thames, G., Hsu, M., ManLam, H., Heber, D., and Li, Z. (2016). Soy protein isolate does not affect ellagitannin bioavailability and urolithin formation when mixed with pomegranate juice in humans. Food Chem. 194: 1300-1303.

Yoshiara, L.Y., Mandarino, J.M.G., Carrão-Panizzi, M.C., Madeira, T.B., da Silva, J.B., de Camargo, A.C., Shahidi, F., and Ida, E.I. (2018). Germination changes the isoflavone profile and increases the antioxidant potential of soybean. J. Food Bioact. 3: 144-150.

Zhang, H., and Tsao, R. (2016). Dietary polyphenols, oxidative stress and antioxidant and anti-inflammatory effects. Curr. Opin. Food Sci. 8: 33-42. 